\title{
Patch Antenna Based on MUC for Wi-Fi and 5G
}

\author{
Suman Nelaturi ${ }^{1 *}$, Nookala Venkata Satya Narasimha Sarma² \\ 1 Department of Electronics and Communication Engineering, Vignan's Foundation for Science, Technology and Research, \\ Guntur 522213, Andhra Pradesh, India \\ 2 Department of Electronics and Communications Engineering, Indian Institute of Information Technology Tiruchirappalli, \\ Tiruchirappalli 620012, Tamil Nadu, India \\ * Corresponding author, e-mail: drns_ece@vignan.ac.in
}

Received: 21 October 2019, Accepted: 03 August 2020, Published online: 15 November 2021

\begin{abstract}
This communication reported the patch antenna working at Wi-Fi and $5 \mathrm{G}$ bands. To acquire compactness the side lengths of the patch are taken based on upper-frequency band (3.3 GHz). Dual-band operation (lower resonating band) is realized by loading the Mushroom Unit Cell (MUC) along the bottom right corner of the patch. To obtain Circular Polarization (CP) at the 5G band the conventional patch is modified with fractal boundary. This blend of the Double Negative Transmission Lines metamaterials (DNG TL), as well as fractal concepts yielded good compactness suitable for ultra-thin portable gadgets. Measured results have good correlation with simulated data from HFSS. The obtained bandwidths at the lower and upper bands are $2.51 \%$ and $6.23 \%$ when the Poly fractal curves are introduced. CP bandwidth of the proposed antenna at $5 \mathrm{G}$ band obtained from the measured data is $2.35 \%$ which is the highest to the best of authors' knowledge for this type of thin antennas.
\end{abstract}

Keywords

dual band, Mushroom Unit Cell (MUC), Double Negative Transmission Line (DNG TL)

\section{Introduction}

Artificial materials like Metamaterials are best alternative for designing thin and compact antennas because of their special electromagnetic properties [1]. These materials will support backward wave propagation, due to which left-handed bands (zeroth order or negative order modes) are produced. Metamaterials or left-handed materials are categorized into ENG materials, MNG materials and DNG materials. Metamaterials are constructed using VIAs, Split Ring Resonators (SRRs). The pioneers in this area analyzed the Metamaterials based on transmission line theory [2]. Wideband antenna with a single layer (single substrate) based on MUC is proposed in [3]. Dual band and multiband antennas with single layer are presented in [4-7]. Dual band antennas based on the multilayer are listed in [8-14]. All these antennas are suffering from the size and resonating frequency ratio ie. Lower resonating frequency occurs at the cost of the large volume of the patch. But the proposed antenna is able to produce a lower resonating band for lower dimensions of the patch.

In this work, patch antenna operating at $\mathrm{Wi}-\mathrm{Fi}$ and $5 \mathrm{G}$ bands is attempted. $\mathrm{CP}$ at patch mode is achieved by providing asymmetry to the patch through the fractal curves embedded along the length and width of patch. Simulations are conducted in Ansoft HFSS.

\section{Structure of reported antenna}

The proposed antenna structure is given in Fig. 1. Described antenna is implemented with dielectric material (Rogers RT/Duroid) has $\epsilon=2.2, h=3.175 \mathrm{~mm}$. Radiating patch is slotted at the right bottom corner to load MUC. The dimensions of the slot are $10 \times 10 \mathrm{~mm}^{2}$. Square MUC having a metallic patch with a side length of $9.5 \mathrm{~mm}$ and a VIA with $0.3 \mathrm{~mm}$ radius is loaded into the patch. The series capacitance due to the gap between patch and MUC and shunt inductance due to VIA are the main cause of getting zeroth order band (left-hand band). The physical parameters of presented antenna are listed in Table 1.

\section{DNGTL theory and simulation results}

DNG TL unit cell equivalent circuit is given in Fig. 2, where $L_{R}$ and $C_{R}$ are series inductance and shunt capacitance per unit length in which both are due to patch and $L_{L}$ is the shunt inductance due to VIA and $C_{L}$ is series capacitance due to the gap between radiating patch and MUC. 


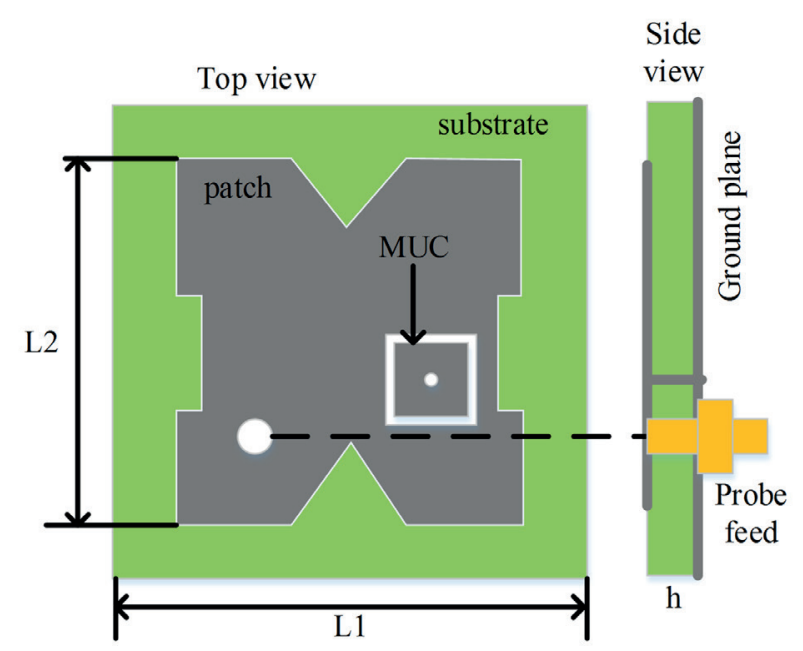

(a)

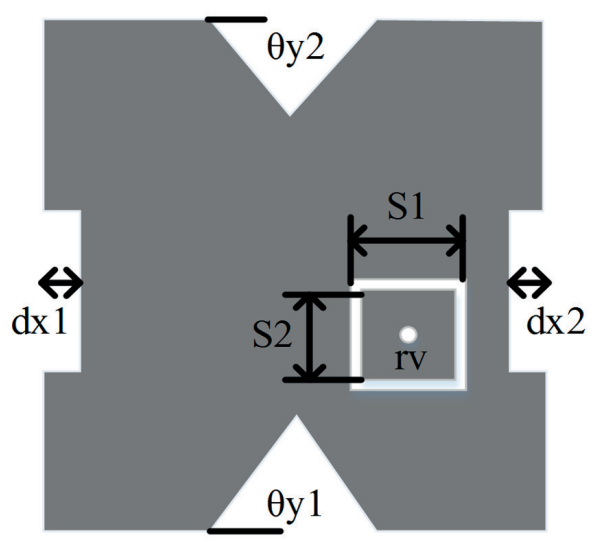

(b)

Fig. 1 (a) Proposed antenna structure; (b) IAs of Poly fractal boundary

Table 1 Parameter values

\begin{tabular}{lccccccc}
\hline Parameter & $L_{1}$ & $L_{2}$ & $S_{1}$ & $\mathrm{~S}_{2}$ & $d x 1=d x 2$ & $h$ & $r_{v}$ \\
\hline Value in $\mathrm{mm}$ & 37 & 27 & 10 & 9.5 & 1.5 & 3.175 & 0.3 \\
\hline
\end{tabular}

The relationship between the phase constant and the angular frequency is given by Eq. (1):

$$
\beta d=\arccos \left(1-0.5 \times\left(\frac{w^{2}}{w_{R}^{2}}-\frac{w_{L}^{2}}{w_{s e}^{2}}-\frac{w_{L}^{2}}{w_{s h}^{2}}+\frac{w_{L}^{2}}{w^{2}}\right)\right)
$$

where $\beta$ is phase constant, $d$ is length of unit cell.

From Eq. (1), it is observed that the phase constant is dependent on four different angular frequencies. Those are patch mode frequency $\left(w_{R}\right)$ or $n=+1$ mode, zeroth order frequency $\left(w_{s h}\right)$ or $n=0$ mode, $w_{s e}$ or $n=-1$ mode and $w_{L}$ or $n=+2$ mode respectively. The proposed antenna is resonating at two frequencies only those are patch mode band and zeroth order band. The phase constant is negative for $n=0$ mode and positive for the $n=+1$ mode. The dispersion characteristics plot of the reported antenna is shown in Fig. 2, which gives the information about Zeroth Order Resonant (ZOR) frequency. Here the ZOR is

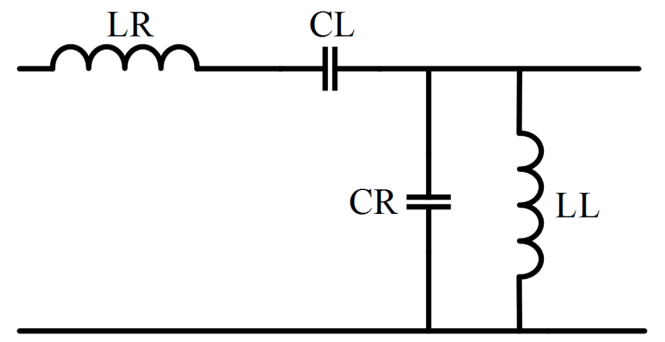

(a)

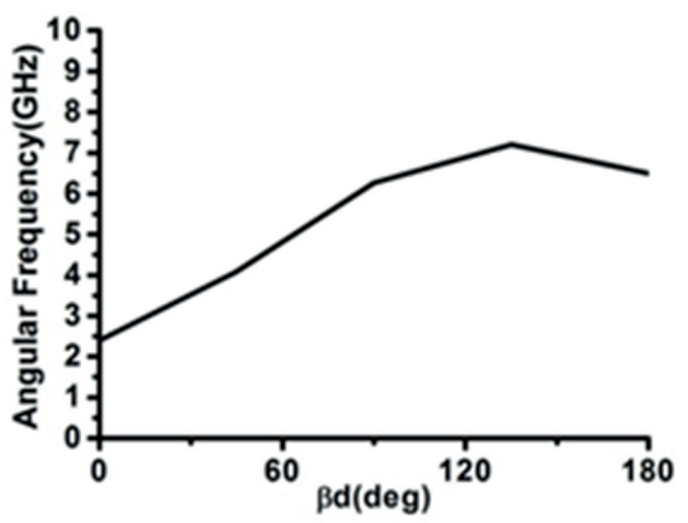

(b)

Fig. 2 DNG TL unit cell (a) Equivalent circuit diagram (b) dispersion characteristics plot

at $2.4 \mathrm{GHz}$ which is independent of the wavelength of the patch (the ZOR frequency occurred at infinite wavelength which is the speciality of the DNG TL).

The construction and development of the reported antenna is given in Fig. 3. At first, the square patch Antel is designed for $5 \mathrm{G}$ band $(3.3 \mathrm{GHz})$ where the polarization is linear. The CP at this single band can be obtained by replacing edges of the square patch with Poly fractal curves which results in Ante2. Ante3 is achieved by inserting MUC along the bottom right corner of Antel to produce two bands with LP. Finally, Ante4 can be designed by

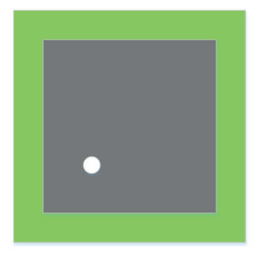

Antel

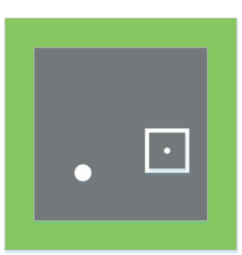

Ante3

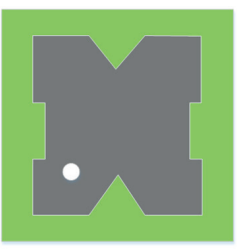

Ante2

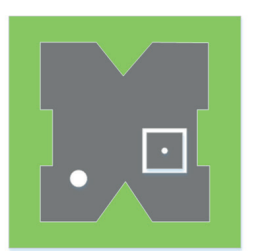

Ante4
Fig. 3 In between steps in the design 
loading MUC in Ante2 to result in dual-band patch antenna with first band LP and the second band with CP. The optimized feed point location is obtained from the software tool which is $4.5 \mathrm{~mm}$ distance away diagonally from the patch center position. Simulated Return Loss (RL) properties of presented antenna are given in Fig. 4 and Table 2.

From Fig. 5, it is observed that, if the dimensions of the square MUC are decreasing, then the left-hand band is moving from left side to right side on the frequency scale. The dimensions of the MUC are optimized $\left(S_{2}=9.5 \mathrm{~mm}\right)$ to get the left-hand band exactly at $2.4 \mathrm{GHz}$.

To interpret the working mechanism of reported antenna, simulated surface current distributions at each frequency band are given in the Fig. 6. The cause for Wi-Fi band (2.4 GHz) is current distribution across MUC. $5 \mathrm{G}$ band $(3.3 \mathrm{GHz})$ is because of strong surface current at sides of fractal patch.

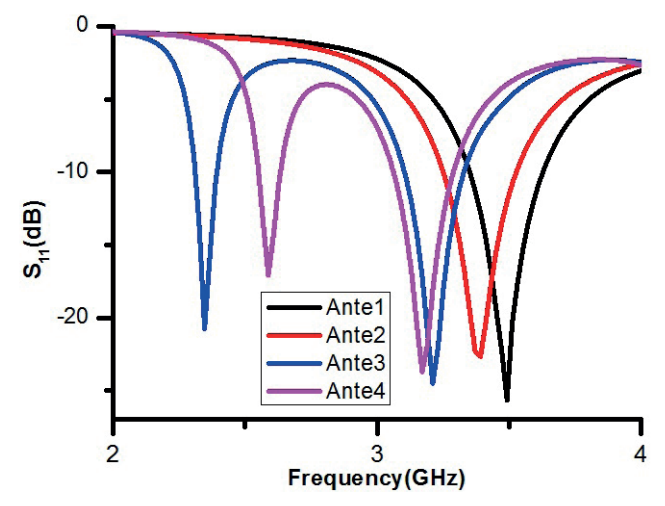

Fig. 4 Simulated RL characteristics

Table 2 Impedance bandwidth values

\begin{tabular}{cccc}
\hline \multirow{2}{*}{ S. No } & Antenna & Band1 & Band2 \\
\hline 1 & Ante1 & ---- & $9.71 \%(3.31-3.73 \mathrm{GHz})$ \\
2 & Ante2 & ---- & $8.21 \%(3.27-3.55 \mathrm{GHz})$ \\
3 & Ante3 & $0.79 \%(2.50-2.52 \mathrm{GHz})$ & $6.26 \%(3.09-3.29 \mathrm{GHz})$ \\
4 & Ante4 & $2.51 \%(2.36-2.42 \mathrm{GHz})$ & $6.23 \%(3.11-3.31 \mathrm{GHz})$ \\
\hline
\end{tabular}

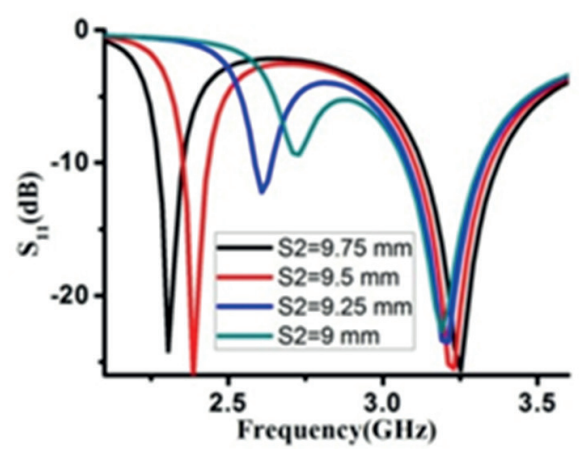

Fig. 5 Optimized RL characteristics

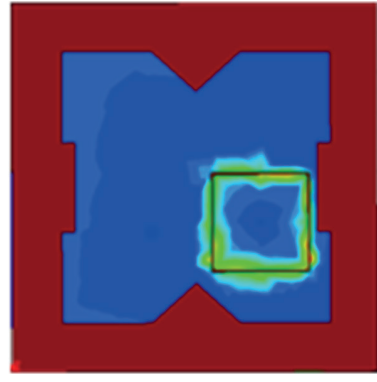

(a)

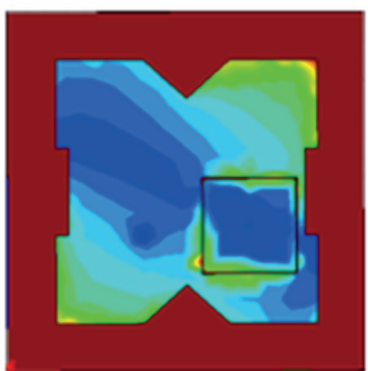

(b)
Fig. 6 Surface current at (a) Wi-Fi band (2.4 GHz), (b) $5 \mathrm{G}$ band (3.3 GHz)

\section{Experimental results}

The demonstrated antenna (Ante4) is manufactured with dielectric material (Rogers RT/Duroid) has dimensions $37 \times 37 \times 3.175 \mathrm{~mm}^{3}$ as shown in Fig. 7. The vertical metallic VIAs (copper wires) are loaded into the patch and ground plane by using through-hole copper technique. Return Loss properties are measured using Agilent 8719A microwave network analyzer. Radiation patterns are obtained from an anechoic chamber with size of $22.5 \times 12.5 \times 11.5 \mathrm{~m}^{3}$. The working frequency of chamber is from $400 \mathrm{MHz}$ to $18 \mathrm{GHz}$.

Return loss characteristics of Ante4 are shown in the Fig. 8. Experimental results are highly correlated with simulated data. Experimental return loss bandwidth of

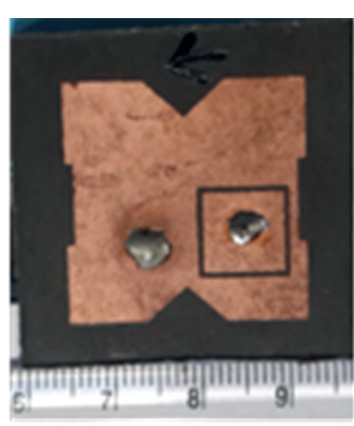

Top View

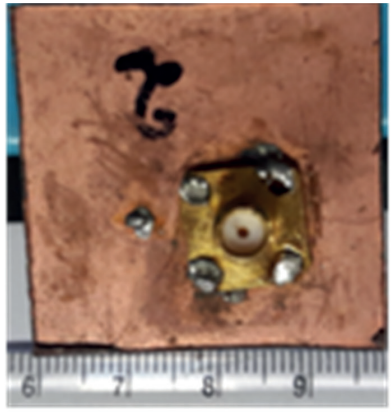

Bottom View
Fig. 7 Prototype of Ante 4

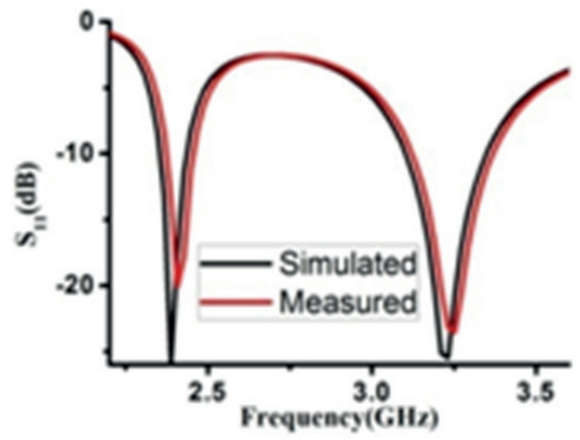

Fig. 8 RL characteristics 
Poly fractal boundary patch antenna is $2.51 \%$ at Wi-Fi band and $6.23 \%$ at $5 \mathrm{G}$ band respectively. The measured AR plot is given in Fig. 9. AR bandwidth at $5 \mathrm{G}$ band is $2.35 \%$. Figs. 10 and 11 represent radiation patterns at Wi-Fi and 5G bands. Fig. 12 describes the gain plot.

Proposed antenna characteristics are compared with existing literature and listed in Table 3. The antennas presented in $[3,6]$ are small in size but their operating frequencies are high with low return loss bandwidth.

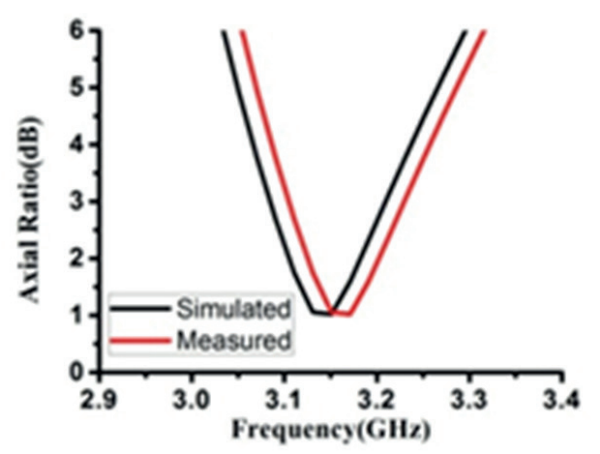

Fig. 9 AR characteristics
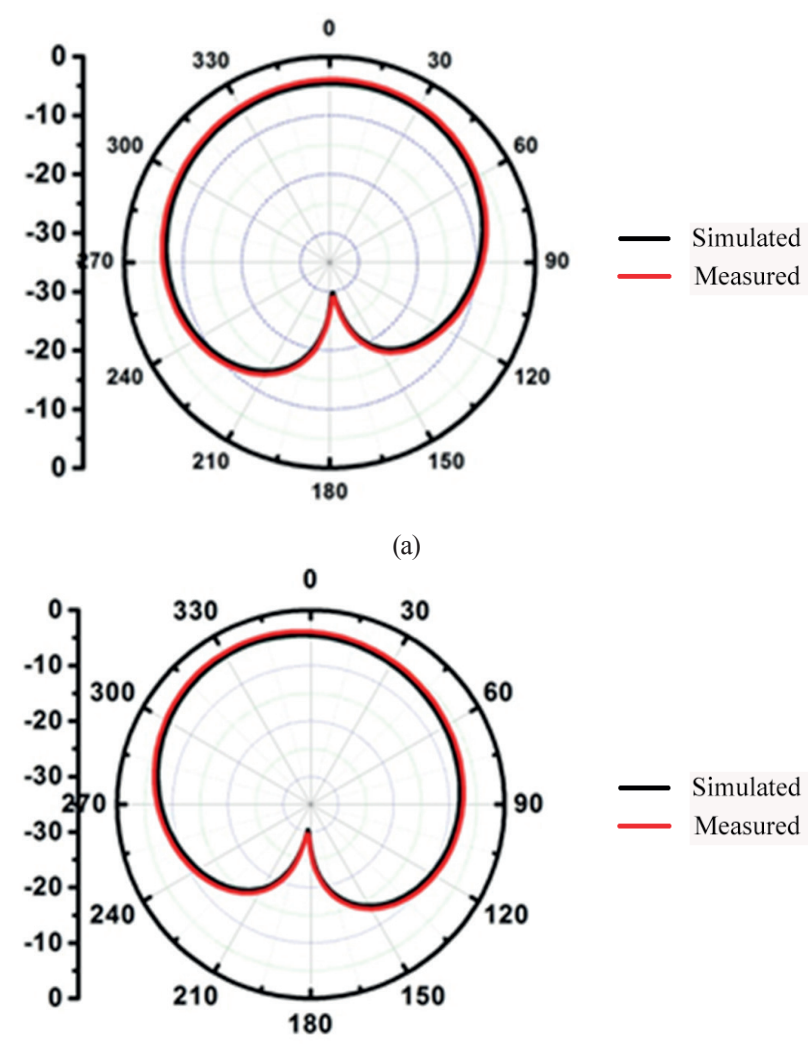

(b)

Fig. 10 Radiation pattern at Wi-Fi band (a) E plane, (b) H plane

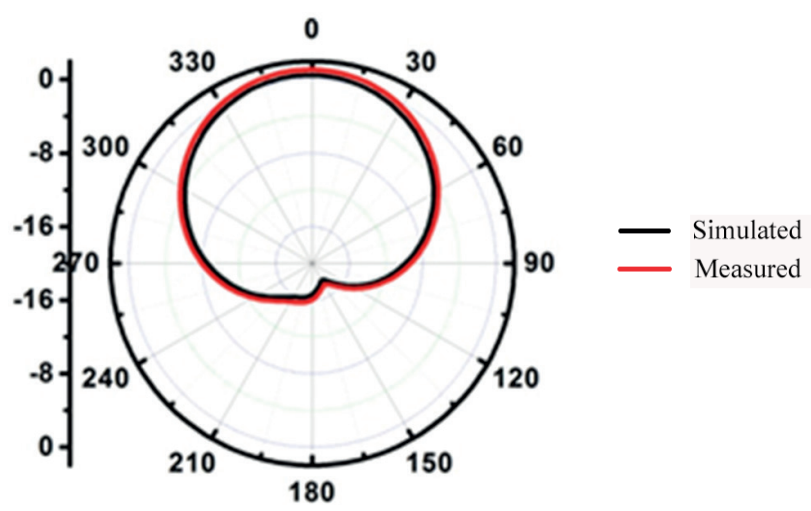

(a)

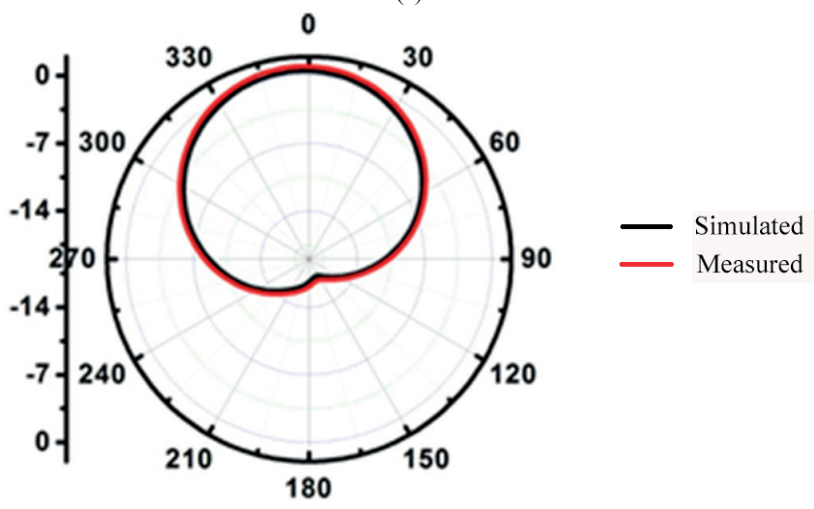

(b)

Fig. 11 Radiation pattern at 5G band (a) E plane, (b) $\mathrm{H}$ plane

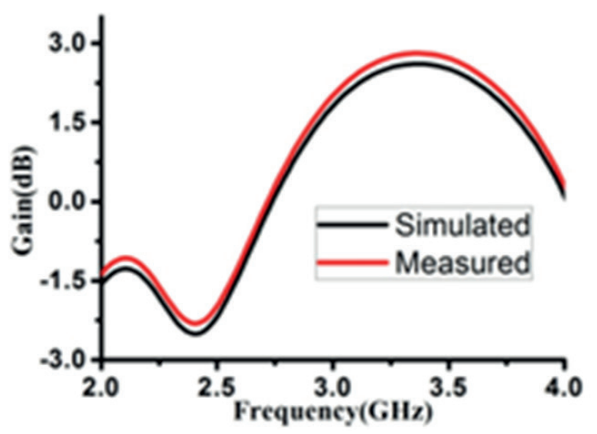

Fig. 12 Gain plot of reported antenna

\begin{tabular}{|c|c|c|c|c|}
\hline \multirow[t]{2}{*}{ Antenna } & \multirow[t]{2}{*}{$\begin{array}{l}\text { Patch Size } \\
(\mathrm{mm} \times \mathrm{mm})\end{array}$} & \multirow[t]{2}{*}{$\begin{array}{c}\text { Substrate size } \\
(\mathrm{mm} \times \mathrm{mm} \times \mathrm{mm})\end{array}$} & \multicolumn{2}{|c|}{$\begin{array}{c}10 \mathrm{~dB} \text { return loss } \\
\text { bandwidth at } \\
\text { corresponding centre } \\
\text { frequency }\end{array}$} \\
\hline & & & At ZOR & $\begin{array}{l}\text { At patch } \\
\text { mode }\end{array}$ \\
\hline $\begin{array}{l}\text { Proposed } \\
\text { antenna }\end{array}$ & $27 \times 27$ & $37 \times 37 \times 3.175$ & $\begin{array}{l}2.51 \% \text { at } \\
2.4 \mathrm{GHz}\end{array}$ & $\begin{array}{c}6.23 \% \text { at } \\
3.4 \mathrm{GHz}\end{array}$ \\
\hline$[3]$ & $16 \times 16$ & $36 \times 36 \times 1.5$ & $\begin{array}{l}1.44 \% \text { at } \\
2.76 \mathrm{GHz}\end{array}$ & $\begin{array}{l}3.05 \% \text { at } \\
5.23 \mathrm{GHz}\end{array}$ \\
\hline$[6]$ & $28.8 \times 28.8$ & $60 \times 60 \times 1.6$ & $\begin{array}{l}3.50 \% \text { at } \\
2.3 \mathrm{GHz}\end{array}$ & $\begin{array}{l}1.96 \% \text { at } \\
2.56 \mathrm{GHz}\end{array}$ \\
\hline [7] & $40.9 \times 40.9$ & $60 \times 60 \times 5$ & \multicolumn{2}{|c|}{$5.59 \%$ at $1.68 \mathrm{GHz}$} \\
\hline
\end{tabular}




\section{Conclusions}

The patch antenna working at $\mathrm{Wi}-\mathrm{Fi}$ and $5 \mathrm{G}$ bands is reported in this communication. By optimizing the dimensions of the MUC, feed point and Poly fractal curves,

\section{References}

[1] Caloz, C., Itoh, T. "Electromagnetic Metamaterials: Transmission Line Theory and Microwave Applications", John Wiley \& Sons, Hoboken, NJ, USA, 2005. https://doi.org/10.1002/0471754323

[2] Park, J. H., Ryu, Y.-H., Lee, J.-G., Lee, J.-H. "Epsilon Negative Zeroth-Order Resonator Antenna", IEEE Transactions on Antennas and Propagation, 55(12), pp. 3710-3712, 2007. https://doi.org/10.1109/tap.2007.910505

[3] Qing, X. N., Chen, Z. N. "A Compact Circularly Polarized Slotted Patch Antenna for GNSS Applications", IEEE Transactions on Antennas and Propagation, 62(12), pp. 6506-6509, 2014. https://doi.org/10.1109/tap.2014.2360218

[4] Amani, N., Jafargholi, A. "Zeroth-Order and TM ${ }_{10}$ Modes in OneUnit Cell CRLH Mushroom Resonator", IEEE Antennas and Wireless Propagation Letters, 14, pp. 1396-1399, 2015. https://doi.org/10.1109/LAWP.2015.2407955

[5] Singh, G. K., Chaudhary, R. K., Srivastava, K. V. "A Compact Zeroth Order Resonating Antenna Using Complementary Split Ring Resonator with Mushroom Type of Structure", Progress In Electromagnetics Research Letters, 28, pp. 139-148, 2012. https://doi.org/10.2528/pier111110709

[6] Saurav, K., Sarkar, D., Srivastava, K. V. "Dual-Polarized DualBand Patch Antenna Loaded With Modified Mushroom Unit Cell", IEEE Antennas and Wireless Propagation Letters, 13, pp. 1357-1360, 2014.

https://doi.org/10.1109/lawp.2014.2337911

[7] Zong, B., Wang, G., Zhou, C., Wang, Y. "Compact Low-Profile Dual-Band Patch Antenna Using Novel TL-MTM Structures", IEEE Antennas and Wireless Propagation Letters, 14, pp. 567-570, 2015. https://doi.org/10.1109/lawp.2014.2372093

[8] El-Raouf, H. E. A., Zaheer, S. S. "Design of small planar antennas based on double layered CRLH metamaterials", Microwave and Optical Technology Letters, 54(10), pp. 2224-2229, 2012. https://doi.org/10.1002/mop.27078 dual-band operation with wide bandwidth is achieved. Return loss bandwidth of the proposed antenna is $2.51 \%$ at Wi-Fi band and is $6.23 \%$ at $5 \mathrm{G}$ band. The $3 \mathrm{~dB}$ AR bandwidth is $2.35 \%$ at the upper resonating band.

[9] Velan, S., Sundarsingh, E. F., Kanagasabi, M., Sarma, A. K., Raviteja, C., Sivasamy, R., Pakkathillam, J. K. "Dual-Band EBG Integrated Monopole Antenna Deploying Fractal Geometry for Wearable Applications", IEEE Antennas and Wireless Propagation Letters, 14, pp. 249-252, 2015. https://doi.org/10.1109/lawp.2014.2360710

[10] Liu, Z. G., Guo, Y. X. "Compact Low-Profile Dual Band Metamaterial Antenna for Body Centric Communications", IEEE Antennas and Wireless Propagation Letters, 14, pp. 863-866, 2015. https://doi.org/10.1109/lawp.2014.2382586

[11] Yue, T., Jiang, Z. H., Panaretos, A. H., Werner, D. H. "A Compact Dual-Band Antenna Enabled by a Complementary Split-Ring Resonator-Loaded Metasurface", IEEE Transactions on Antennas and Propagation, 65(12), pp. 6878-6888, 2017.

https://doi.org/10.1109/tap.2017.2758821

[12] Aboualalaa, M., Abdel-Rahman, A. B., Allam, A., Elsadek, H., Pokharel, R. K. "Design of Dual Band Microstrip Antenna with Enhanced Gain for Energy Harvesting Applications", IEEE Antennas and Wireless Propagation Letters, 16, pp. 1622-1626, 2017. https://doi.org/10.1109/lawp.2017.2654353

[13] Nelaturi, S., Sarma, N. V. S. N. "CSRR based patch antenna for Wi-Fi and WiMAX Applications", Advanced Electromagnetics, 7(3), pp. 40-45, 2018. https://doi.org/10.7716/aem.v7i3.700

[14] Nelaturi, S., Sarma, N. V. S. N. "A Compact Microstrip Patch Antenna Based on Metamaterials for Wi-Fi and WiMAX Applications", Journal of Electromagnetic Engineering and Science, 18(3), pp. 182-187, 2018. https://doi.org/10.26866/jees.2018.18.3.182 